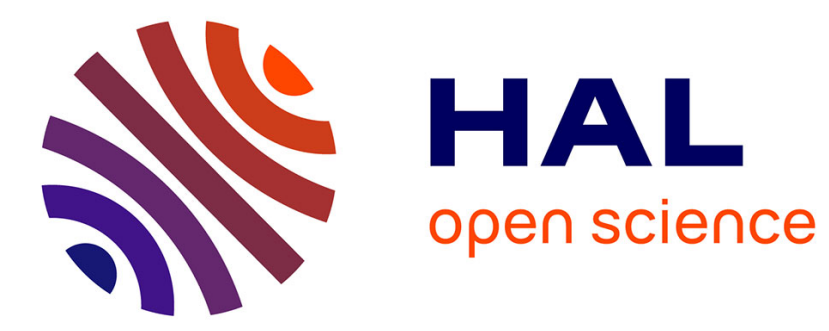

\title{
Eddying vs. laminar ocean circulation models and their applications
}

Bernard Barnier, Thierry Penduff, Clothilde Langlais

\section{To cite this version:}

Bernard Barnier, Thierry Penduff, Clothilde Langlais. Eddying vs. laminar ocean circulation models and their applications. Operational Oceanography in the 21st Century, 2010. hal-02879792

\section{HAL Id: hal-02879792 \\ https://hal.science/hal-02879792}

Submitted on 24 Jun 2020

HAL is a multi-disciplinary open access archive for the deposit and dissemination of scientific research documents, whether they are published or not. The documents may come from teaching and research institutions in France or abroad, or from public or private research centers.
L'archive ouverte pluridisciplinaire HAL, est destinée au dépôt et à la diffusion de documents scientifiques de niveau recherche, publiés ou non, émanant des établissements d'enseignement et de recherche français ou étrangers, des laboratoires publics ou privés. 


\title{
Eddying vs. laminar ocean circulation models and their applications
}

\author{
Bernard Barnier $^{1}$, Thierry Penduff ${ }^{1,2}$, and Clothilde Langlais ${ }^{3}$ \\ ${ }^{1}$ Laboratoire des Ecoulements Géophysiques et Industriels, Centre National de la Recherche \\ Scientifique, Université Joseph Fourier - Grenoble I, France \\ ${ }^{2}$ Presently visitor at the Earth, Ocean and Atmospheric Science Department, The Florida \\ State University, Tallahassee, Florida, USA.
}

${ }^{3}$ CSIRO, University of Tasmania, Hobart, Tasmania, Australia.

\begin{abstract}
Mesoscale eddies are ubiquitous and very energetic features of the ocean circulation. They are represented in the high resolution models used for ocean forecasting, but not yet in today's laminar, coarse-resolution ocean components of models of the climate system. However, advances in high performance computing are likely to change this in a near future, as the next decade should see the use of eddying models to become more and more frequent in the broader context of the Earth system modelling. This lecture discusses mesoscale eddies in models of different resolution. The course is organised as follows. Section 1 introduces the notion of mesoscale eddies by an illustration of the ubiquity of oceanic eddies from satellite observations. Then, it provides a definition of ocean mesoscale eddies by analogy with the atmospheric synoptic eddies. The main impacts of ocean mesoscale eddies on the general circulation are recalled. Section 2 discusses some ocean model fundamentals that link primitive equations with resolution, parameterisation and numerics. The separation between resolved and unresolved scales that results from the choice of grid resolution is discussed, a definition of eddying and laminar resolution models is provided, and the notion of subgridscale parameterization is illustrated with the example of the mesoscale eddies. Section 3 illustrates the tight link that exists between resolution and numerics. Examples are shown where the use of advanced numerical schemes improves model solutions in a more drastic way than increases in resolution. Section 4 uses the DRAKKAR hierarchy of global ocean circulation models (whose resolutions vary between $2^{\circ}$ and $1 / 12^{\circ}$ ) to illustrate how the changes in resolution impact the realism of model simulations, in terms of mean state and variability. The conclusion summarizes the major items discussed during the class.
\end{abstract}


Eddying vs. laminar ocean circulation models and their applications ............ 1

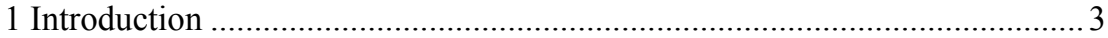

1.1 Ubiquity of eddies in the ocean ........................................................... 3

1.2 Ocean mesoscale eddies: a definition...................................................... 5

1.3 Importance of mesoscale eddies............................................................. 7

2 Some resolution issues in ocean models ........................................................ 7

2.1 Resolved and unresolved scales of motion......................................... 7

2.2 Eddying versus laminar ocean models .............................................. 9

2.3 Parameterisation of mesoscale eddies in laminar models...................... 11

3 Advanced numerical schemes and resolution .............................................. 13

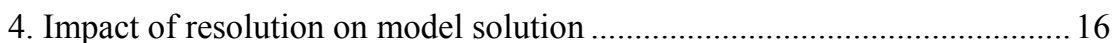

4.1 DRAKKAR hierarchy of model configurations .................................. 16

4.2 Some impacts of resolution increase ............................................... 19

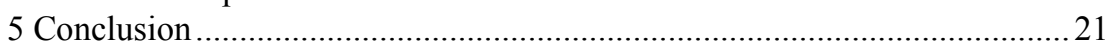

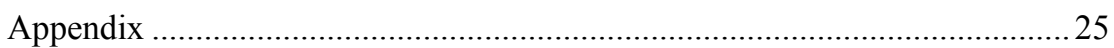




\section{Introduction}

This course deals with resolution issues in numerical models of the ocean circulation, and more specifically with the representation by these models of the mesoscale eddies. Therefore, two classes of models are distinguished in this lecture. One class of models uses "coarse-resolution" grids and solutions produced are characterised by "laminar" dynamical regimes where mesoscale eddies cannot emerge. The other class of models uses "high-resolution" grids, and solutions produced are characterised by "eddying" regimes where mesoscale eddies can emerge and develop. In this paper, the words "laminar" and "eddying" are used to qualify the dynamical regimes of the flows produced by the models, whereas the words "coarse" and "high" are used to label the resolution of the numerical grids.

\subsection{Ubiquity of eddies in the ocean}

The ubiquity of eddies in the ocean has been demonstrated by a large numbers of studies using satellite (e.g. altimetry, see Chelton et al., 2007) and in-situ instruments. This is illustrated in Fig. 1a which presents the Sea Level Anomalies (SLA) observed by satellite altimetry on 19/05/2004. The ocean appears full of features of a few hundred kilometres scale. These observed features live typically from a few days to a few months, some features persisting for more than two years (Chelton et al., 2007).

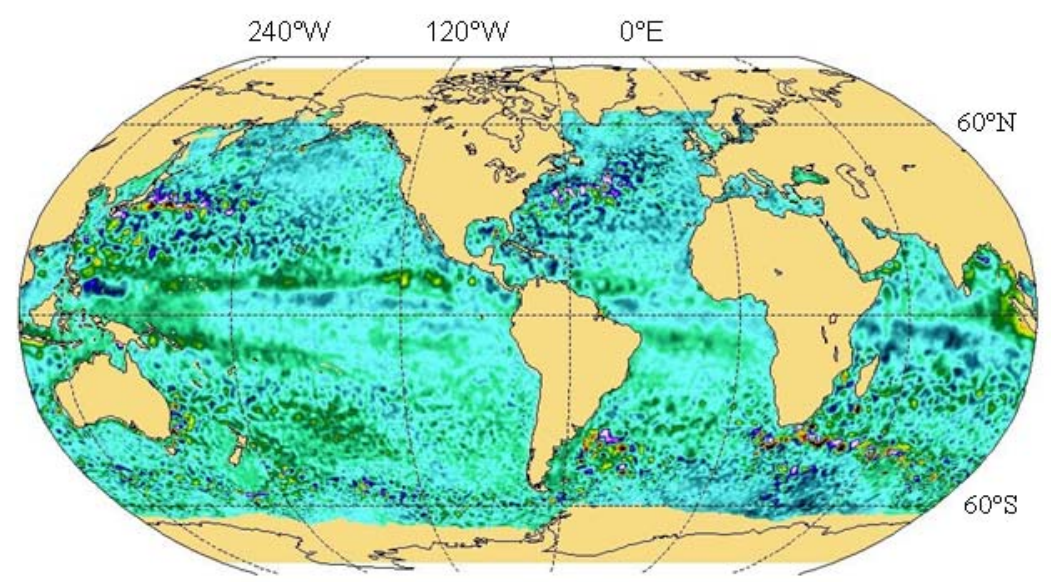

a) Satellite altimetry (Aviso) 


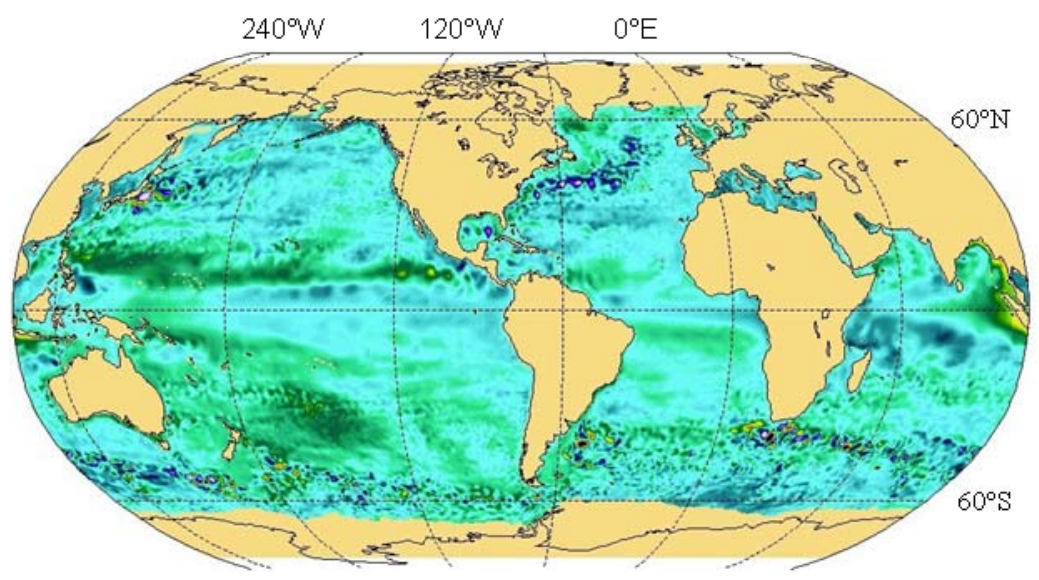

b) Drakkar $14^{\circ}$ model

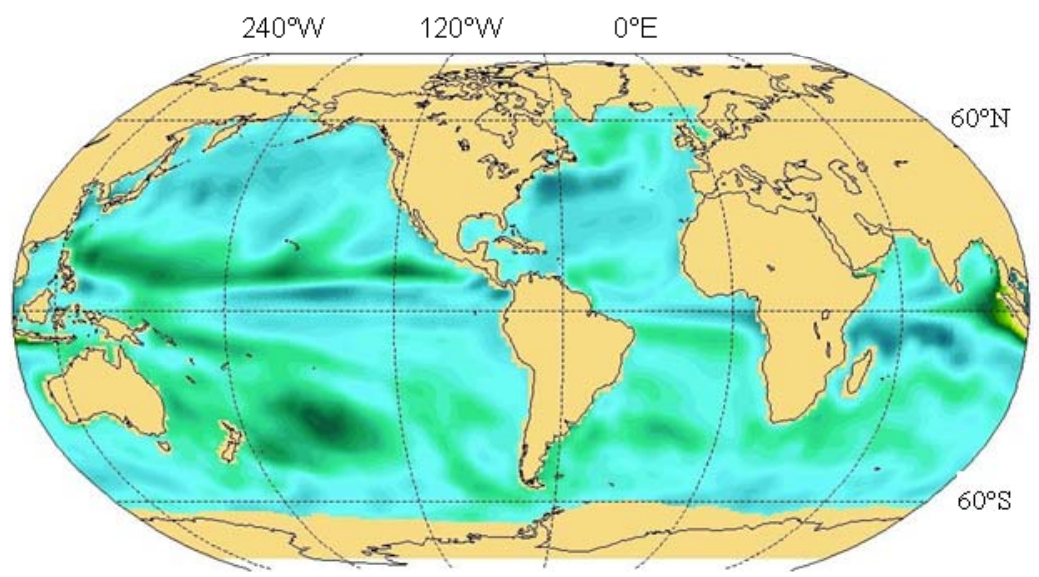

c) Drakkar $2^{\circ}$ model

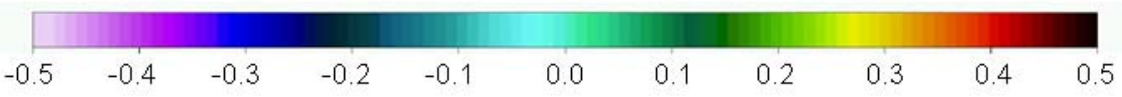

Fig. 1. Sea level anomaly (in meters) on 19/05/2004, a) as observed by satellite altimetry (Aviso product), and as simulated by b) a $1 / 4^{\circ}$ eddy-permitting global model (Drakkar model ORCA025, run series G70) and c) a $2^{\circ}$ coarse resolution global model (Drakkar model ORCA2, run series G70). Both models use the same numerical code (NEMO) and the same atmospheric forcing (DFS3, see text).

While atmospheric and topographic influences also play a role, these eddies are thought to be mostly generated by the instabilities of major currents; this explains why a greater concentration of strong mesoscale features is found in the vicinity of boundary currents and their offshore extension (e. g. Gulf Stream, Kuroshio), and in the Antarctic Circumpolar Current. These features are also ubiquitous in the 
centre of the subtropical gyres and in the eastern part of mid-latitude ocean basins (also prone to dynamical instabilities). Mesoscale eddies are also generated along the equator (these are significantly larger and often more anisotropic) and in the interior of the ocean (near topographic obstacles, or through shear instabilities, etc). In short, modern observations reveal a "sea of mesoscale eddies" whose general characteristics relate to larger-scale circulation patterns, and which are separated by smaller (so-called sub-mesoscale) dynamical structures with enhanced anisotropy.

\subsection{Ocean mesoscale eddies: a definition.}

Ocean mesoscale variability in the ocean appears in a variety of transient features such as eddies, meanders, rings, waves and fronts with space scales of a few 10th to 100 th $\mathrm{km}$ and time scales of 10-100 days. Ocean eddies spontaneously arise from the hydrodynamic instability of the major large scale current systems, as do the atmospheric synoptic features from instability of the large scale wind systems. Ocean mesoscale eddies are often described as being the "weather system" of the global ocean, by a dynamical analogy with the synoptic features of the atmosphere (McWilliams 2008).

Let us consider a mean oceanic or atmospheric flow in a vertically-stratified fluid. The vertical stratification is characterised by the Brunt-Vaïsala frequency $\mathrm{N}$ :

$$
N^{2}=\frac{g}{H} \frac{\Delta \rho}{\rho_{0}}
$$

$\mathrm{H}$ is the characteristic scale of the vertical shear of the mean flow (e.g. the thickness of the ocean main thermocline or the atmospheric troposphere height), $\rho_{0}$ a reference density, $\Delta \rho$ the bulk density gradient over $H$, and $g$ the gravitational acceleration.

Let us define $U$ as the eddy characteristic velocity scale, $L$ as the characteristic eddy horizontal scale, and $f$ the Coriolis parameter. Dynamically, ocean mesoscale (and atmospheric synoptic) eddies can be defined as features that:

- $\quad$ are in quasi-geostrophic equilibrium (i.e. a small Rossby number):

$$
R_{0}=\frac{U}{f L}<<1
$$

- have a characteristic velocity small compared to the celerity of (internal) gravity waves (i.e. a small Froude number): 


$$
F_{r}=\frac{U}{\sqrt{g^{\prime} H}}=\frac{U}{N H}<<1 \quad \text { with } \quad g^{\prime}=g \frac{\Delta \rho}{\rho_{0}}
$$

- $\quad$ are generated by instabilities of the large scale flow, and as such, are equally influenced by stratification and rotation (i.e. order one Burger number):

$$
B_{u}=\frac{R_{0}^{2}}{F_{r}^{2}}=\left(\frac{N H}{f L}\right)^{2}=O(1)
$$

The characteristic eddy horizontal scale can be readily estimated from the equation $B_{u}=1$ as:

$$
L=\frac{N H}{f}
$$

Typical atmospheric values for $N=10^{-2} \mathrm{~s}^{-1}$ and $H=10^{4} \mathrm{~m}$ yield a mid-latitude (i.e. $f=10^{-4} \mathrm{~s}^{-1}$ ) synoptic eddy length-scale of $L_{\text {atm }}=1000 \mathrm{~km}$. Typical ocean values of $N=5 \times 10^{-3} \mathrm{~s}^{-1}$ and $H=10^{3}$ m yield a mesoscale eddy length-scale of $L_{o c e}=50 \mathrm{~km}$. The typical eddy length-scale is therefore 20 times smaller in the ocean.

The dynamical impact of these eddies on the global circulation is likely to be very different, at least quantitatively, in the two fluids, and the analogy between ocean and atmospheric eddies might not hold beyond this scale analysis. For example, it is clear that atmospheric eddies, because of their much greater size, are much more efficient in transporting heat from subtropical to subpolar latitudes. Indeed, atmospheric synoptic eddies are almost responsible for the whole poleward heat transport from $30^{\circ}$ to $60^{\circ}$ latitude, and the necessity to resolve these features in atmospheric general circulation models was never questioned.

The smaller size of ocean eddies suggests a weaker effectiveness in transporting heat (and salt) poleward, especially since a large part of the meridional heat transport is done (at least in part of the northern hemisphere ocean) by mean currents flowing poleward along continents (continents allow the maintenance of strong, localized zonal pressure gradients in the ocean geostrophically balanced with poleward boundary currents). Although the importance of the eddy transport is recognized, the necessity of resolving eddies in ocean general circulation models (OGCMs) is still under debate, and models used for climate prediction are still laminar, i.e. using coarse-resolution grids, relying on parameterisations to account for the effects of mesoscale eddies on larger scales. 


\subsection{Importance of mesoscale eddies}

Eddies are ubiquitous features in the ocean and contain a great part of the kinetic energy of the ocean. Similarly to the atmospheric weather systems, their transport of energy is crucial to the dynamical balance of the circulation at global scale. They are important because they feedback on the large scale circulation and have a significant contribution to the total ocean heat fluxes. Eddy processes also have an important impact on the generation and maintenance of strong currents and fronts and of water mass physical and biogeochemical properties, as they are major actors of air-sea exchanges, isopycnal dispersion and mixing, density restratification, ventilation and subduction, energy cascade and dissipation, topographic form stress, etc. (McWilliams, 2008). Eddies are also source of intrinsic climate variability. They have great impacts on marine ecosystems, and are very important for operational ocean applications such as marine safety, pollution dispersion, offshore industry, fisheries, etc.

\section{Some resolution issues in ocean models}

\subsection{Resolved and unresolved scales of motion}

Ocean models fundamentals have been recently thoroughly revisited in a series of papers by (Griffies 2004, Griffies et al. 2005, Treguier 2006, Griffies and Adcroft 2008). The present course focuses on the resolution issue, and the reader should refer to the above papers for more elements on the equations and numerical algorithms used in numerical models of the ocean general circulation. Ocean general circulation models usually solve for the so-called primitive equations (Madec 2008, for example), which are an approximation of the Navier-Stokes equations, and a nonlinear equation of state which couples two active tracers (temperature $T$ and salinity $S$ ) with density $\rho$.

The most important assumptions, based on scale considerations, are (i) the thinshell (or shallow water) approximation (the ocean depth is much smaller than the earth's radius), (ii) the Boussinesq approximation (density variations are neglected except in their contribution to the buoyancy force), (iii) the hydrostatic hypothesis (the vertical momentum equation is reduced to a balance between the buoyancy force and the vertical pressure gradient), and (iv) the incompressibility hypothesis (the three dimensional velocity vector is non divergent).

For the purpose of this course, the Primitive Equations (PEs) are written as in (Treguier 2006): 


$$
\frac{\partial Y}{\partial t}+\mathbf{u} \cdot \nabla Y+F(Y)=0
$$

$\mathbf{u}=(u, v, w)$ is the $3 \mathrm{D}$ velocity vector, $Y=(\mathbf{u}, T, S)$ is the prognostic continuous state vector of the ocean, and $F(Y)$ includes all other terms of the PEs, including the Coriolis force, the pressure gradient force, the external forcing, etc. Because this lecture focuses on mesoscale eddies, one shall consider that the $F(Y)$ term in (6) also includes the parameterisation of diapycnal mixing induced by small scale 3-D turbulence (see (Large et al. 1994, Large 1998) for a review of small scale turbulence closure models). A more standard form of the primitive equations is given in the Appendix.

Equation (6) is solved numerically, which means that PEs are discretised on a grid using finite difference schemes (or other numerical methods). Solving the PEs numerically means applying a "discretisation" operator ()$_{R}$ to the state vector $Y$ and its equation of evolution (6), which yields:

$$
\frac{\partial Y_{R}}{\partial t}+(\mathbf{u} \cdot \nabla Y)_{R}+(F(Y))_{R}=0
$$

Where $Y_{R}=(Y)_{R}$ is the model solution (or i.e. a discrete representation of the state of the ocean). Following Treguier (2006), (7) can be rewritten as:

$$
\frac{\partial Y_{R}}{\partial t}+\mathbf{u}_{R} \cdot \nabla Y_{R}+F_{R}\left(Y_{R}\right)=-\left((\mathbf{u} \cdot \nabla Y)_{R}-\mathbf{u}_{R} \cdot \nabla Y_{R}\right)-\left((F(Y))_{R}-F_{R}\left(Y_{R}\right)\right)
$$

\section{Evolution equation of the resolved state of the ocean}

\section{Effects of the unresolved scales on the resolved state of the ocean}

The numerical model integrates (8) in time, providing successive values of $Y_{R}$, the discrete state of the ocean, at spatial scales larger than the grid step and at discrete times. Note that the evolution equation for the discrete state (8) has the same left-hand side as its continuous counterpart (6), but with additional contributions on the right-hand side (RHS) that represent the effects of unresolved scales on the resolved model solution. The definition of the resolved and unresolved scales involves averaging operators (Griffies 2004). The RHS term of (8) is generally unknown. A solution used in models to calculate this term often consists in an empirical relationship or a physically based model (i.e. a parameterisation or a subgridscale model). Such models express the contribution of unresolved processes on the resolved state following an approach similar to the "turbulent closure hypothesis" that yields higher-order moments as a function of lower-order moments (Lesieur, 2008). 


\subsection{Eddying versus laminar ocean models}

Choosing the grid resolution of an ocean general circulation model (OGCM) is formally equivalent to the choice of an appropriate averaging operator (low-pass filtering at the grid step) and an appropriate approach to estimate the contribution of smaller scales (i.e. the $R H S$ of (8)). If the operator ()$_{R}$ has the properties of a Reynolds Operator, i.e. if the unresolved (or subgridscale) part of the ocean state vector $Y$, defined as $Y^{\prime}=Y-Y_{R}$, verifies $\left(Y^{\prime}\right)_{R}=0$ (and if the flow verifies properties of stationarity and ergodicity, see (Lesieur, 2008) for details), then the part of the unresolved effects that corresponds to the non linear advection (i.e. the first term in the $R S H$ of (8)), can be expressed in the form of a divergence of eddy fluxes:

$$
\left((\mathbf{u} \cdot \nabla Y)_{R}-\mathbf{u}_{R} \cdot \nabla Y_{R}\right)=\nabla \cdot\left(\mathbf{u}^{\prime} Y^{\prime}\right)_{R}
$$

We do not discuss in this course the treatment of the second term of the RHS of (8), which includes the unresolved but nonetheless important effects of the forcing. In the following we assume that it is included in the term $F_{R}\left(Y_{R}\right)$. The discretised model equation (8) becomes:

$$
\frac{\partial Y_{R}}{\partial t}+\mathbf{u}_{R} \cdot \nabla Y_{R}+F_{R}\left(Y_{R}\right)=-\nabla\left(\mathbf{u}^{\prime} Y^{\prime}\right)_{R}
$$

The RHS of (10) (namely the "Reynolds stresses" if $Y$ is momentum, and the turbulent heat fluxes if $Y$ is potential temperature) is a matter for eddy parameterisation.

When choosing the resolution of a model, one has to answer the question of which "eddy effects" should be explicitly simulated to address the given scientific question. For example, one expects different answers to forecast ocean currents and fronts in the short term (in that case, eddies should be resolved explicitly, requiring fine, computationally-expensive grids), or to simulate multi-decadal changes of the ocean meridional heat transport, (in which case eddy effects may be parameterised on coarse, computationally-efficient grids).

A model will be "eddying" if it uses

- a horizontal grid mesh, whose resolution is fine enough to let mesoscale dynamics emerge, i.e. baroclinic and barotropic instability processes are explicitly (albeit partly) resolved;

- an appropriate representation of the effects of the unresolved (smaller) scales on resolved (mesoscale) features.

In practice, this means having a grid mesh finer than the eddy length scale (see Fig. 2, typically a grid mesh of the order of $10 \mathrm{~km}$ or finer for an eddy scale (5) of $50 \mathrm{~km}$ ). The effects of the unresolved scales on the mesoscale dynamics are often 
parameterised by a hyper-viscosity (e.g. biharmonic), an approach that ensures numerical stability but that is not fully satisfactory physically. Research is underway to develop more consistent alternatives (e.g. Frisch et al., 2008).

A model will be "laminar" if it uses

- a coarse horizontal grid mesh whose resolution does not let mesoscale features emerge;

- an appropriate representation of the effects of the mesoscale features on resolved (e.g. basin-scale) features.

In practice, this means having a mesh looser than the eddy length scale (see Fig. 2, typically a grid mesh of the order of 50 to $100 \mathrm{~km}$ for an eddy scale (5) of $50 \mathrm{~km}$ ). In coarse resolution modelling, the effects of the mesoscale scales on the largescale dynamics rely on parameterisations that should account for both the diffusive and the advective effects of mesoscale eddies.

Note that the same equation (10) in integrated in time in both "eddying" and "laminar" models, but unresolved features have different spatial scales in each case: their impact on resolved scales must be represented by distinct parameterisations in both classes of models (opening two separate ways of model developments). The next section presents a parameterisation of mesoscale eddies that is widely used in laminar models.

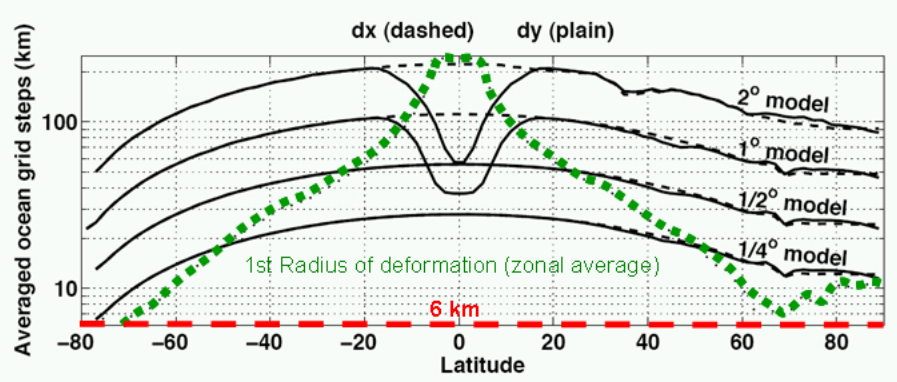

Fig. 2. Variation of the horizontal grid resolution (in $\mathrm{km}$ ) with latitude in the Drakkar hierarchy of global models (resolutions from $2^{\circ}$ to $1 / 4^{\circ}$ ). The dashed green line shows the variation of the first radius of deformation ( $\sim$ the eddy length scale). The full (dashed) black lines show the size of the computational mesh in the meridional (zonal) direction. The coarse resolution models $\left(2^{\circ}\right.$, $1^{\circ}$ and $1 / 2^{\circ}$ ) have a meridional mesh that is finer than the eddy scale in the equatorial band only (local meridional refinement of $2^{\circ}$ and $1^{\circ}$ grids). The $1 / 4^{\circ}$ (eddying) model has a grid mesh finer than the first radius of deformation between $40^{\circ} \mathrm{N}$ and $40^{\circ} \mathrm{S}$. An "eddy resolving" model at all latitudes should aim at a resolution of the order of $10 \mathrm{~km}$ or better at the equator. This is almost obtained by the $1 / 12^{\circ}$ Drakkar model configuration under development (adapted from Penduff et al. 2010). 


\subsection{Parameterisation of mesoscale eddies in laminar models}

The representation of the effects of the mesoscale eddies on the large scale ocean circulation is a key issue for ocean models used for modelling the climate system. As we have mentioned in the introduction, these effects are numerous. However, there is no parameterisation that accounts for all of them, and the parameterisation of mesoscale eddies is an active area of fundamental research (Eden and Greatbatch 2008, Zhao and Vallis 2008).

The ability of mesoscale eddies to mix tracers along isopycnal surfaces is, among all eddy properties, one that has the greatest impact on the density and tracer distribution at the large scales, and it must be parameterised in coarse resolution ocean climate models. In this course, we discuss a now classical approach to mimic this effect. Writing (10) for potential temperature $T$ yields:

$$
\frac{\partial T_{R}}{\partial t}+\mathbf{u}_{R} \cdot \nabla T_{R}=-\nabla \cdot\left(\mathbf{u}^{\prime} T^{\prime}\right)_{R}+D_{T}+F_{T}
$$

Consistent with the notations used in the course, $T_{R}$ and $\mathbf{u}_{R}=\left(u_{R}, v_{R}, w_{R}\right)$ are the potential temperature and current velocity vector calculated by the model on a coarse discrete mesh, so $\left(\mathbf{u}^{\prime} T^{\prime}\right)_{R}$ represents the unresolved (mesoscale) eddy fluxes of heat, whose divergence must be estimated to close the equation. The terms $D_{T}$ and $F_{T}$ denote the diapycnal fluxes and the forcing (the $F_{R}\left(Y_{R}\right)$ term of (10)).

Parameterising the mesoscale eddy fluxes means formulating their effects on the model solution $T_{R}$ with a physically based theoretical model. Such model commonly consists in a relationship linking the eddy fluxes $\left(\mathbf{u}^{\prime} T^{\prime}\right)_{R}$ with the gradients of the resolved scales $\nabla T_{R}$. This relationship can be formally written in a tensor form as follows:

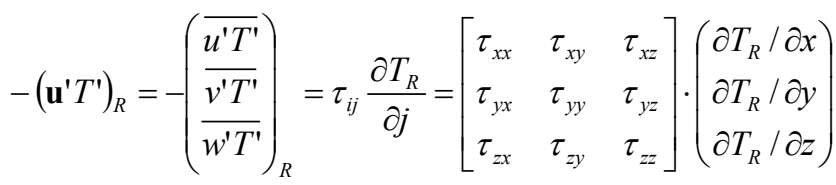

$\tau_{i j}$ is the mixing tensor, and $x, y, z$ indicate the principal mixing directions (here for simplicity the principal axes of the coordinate system). Following Müller (2006), the mixing tensor is split into a symmetric part, $K_{i j}$, and an anti-symmetric part, $S_{i j}$, such that (12) writes as:

$$
\tau_{i j} \frac{\partial T_{R}}{\partial j}=K_{i j} \frac{\partial T_{R}}{\partial x_{j}}+S_{i j} \frac{\partial T_{R}}{\partial x_{j}}
$$


Still following Müller (2006), the contribution of the symmetric tensor $K_{i j}$ to the flux divergence can be expressed in the form of a Laplacian diffusion of heat (as $K_{T} \Delta T_{R}$ ), and that of the anti-symmetric (or skew) tensor $S_{i j}$ can be expressed as a simple advection of heat by a skew (or bolus) velocity vector $\mathbf{V}^{*}\left(\right.$ as $-\mathbf{V}^{*} \cdot \nabla T_{R}$ ). The divergence of the eddy fluxes (12) may thus be written as:

$$
-\nabla\left(\mathbf{u}^{\prime} T^{\prime}\right)_{R}=K_{T} \Delta T_{R}-\mathbf{V}^{*} \cdot \nabla T_{R}
$$

The challenge of the parameterisation of the mesoscale eddy fluxes is then reduced to the determination of $K_{T}$ (a turbulent diffusion coefficient) and $\mathbf{V}^{*}$ the bolus velocity.

In practice in ocean models, the Laplacian diffusion of heat (the first term in the RHS of (14)) acts only along isopycnal surfaces (Redi 1982) to account for the interior isopycnal mixing made by mesoscale eddies. Its contribution in the diapycnal direction is neglected in front of the vertical mixing induced by small scale 3D turbulence. The value of the diffusion coefficient $K_{T}$ is generally user- and application-dependent, and may be constrained by numerical stability considerations. An expression for second term of the RHS in (14) is provided by the GM90 parameterisation (Gent and McWilliams 1990) which mimics the effects of the (unresolved) eddy advection of heat on the resolved (large-scale) buoyancy field. This parameterisation uses the local isopycnal slopes to define a $3 \mathrm{D}$, non divergent bolus velocity $\mathbf{V}^{*}=\left(u^{*}, v^{*}, w^{*}\right)$ in the following form:

$$
\left(u^{*}, v^{*}\right)=\frac{\partial}{\partial z}\left(K_{*} \frac{\vec{\nabla} \rho_{R}}{\partial \rho_{R} / \partial z}\right) ; \quad w^{*}=\vec{\nabla}_{H} \cdot\left(K_{*} \frac{\vec{\nabla} \rho_{R}}{\partial \rho_{R} / \partial z}\right) ; \quad \vec{\nabla} \cdot \vec{V}^{*}=0
$$

where $\rho_{R}$ is the resolved density field. The effect of $\mathbf{V}^{*}$ is to release potential energy from the large scale flow in a way that is physically consistent with the way mesoscale eddies generated by baroclinic instability flatten isopycnals, i.e. extract potential energy from the mean flow. In other terms, eddies induce a downgradient diffusion of the thickness of isopycnal layers along isopycnal surfaces, with a diffusion coefficient $K^{*}$.

In summary, the temperature equation that is solved with the GM90 eddy parameterisation has the following form (the same holding for salinity):

$$
\frac{\partial T_{R}}{\partial t}+\left(\mathbf{u}_{R}+\mathbf{V}^{*}\right) \cdot \nabla T_{R}=+K_{T} \Delta_{\rho} T_{R}+F_{T}
$$

$\Delta_{\rho}$ indicates the two dimensional Laplacian operator acting along the local isopycnal surfaces defined by (Redi 1982). All terms in (16) are now expressed as a function of the resolved variables $T_{R}$ and $\mathbf{u}_{R}$, eddy effects are accounted for by the Laplacian diffusion term, and the bolus velocity term. Both latter terms have been 
derived under the physical assumption that eddies mix properties along isopycnal surfaces, and have been expressed using the mathematical formalism of the mixing tensor. The parameterisation of the eddy fluxes on the resolved density field is then reduced to the determination of the temperature and thickness diffusion coefficients, $K_{T}$ and $K_{*}$. The evaluation of these coefficients is still partly empirical. The GM90 parameterisation has been proved to significantly improve the largescale density field and circulation in coarse resolution simulations, and is the most widely used parameterisation of mesoscale eddies in ocean climate models.

\section{Advanced numerical schemes and resolution}

Although the GM90 parameterisation and its variants evolutions are a recognized improvement for coarse resolution models, many eddy effects are not yet accounted for in these models. In addition, more and more ocean model applications require an explicit resolution of mesoscale eddies, especially in ocean forecasting. Consequently, the use of eddying models is rapidly growing. But increasing resolution is not as simple as increasing the grid mesh. As finer space and time scales appear in model solutions when resolution increases, the subgridscale parameterisations need to evolve (since they will have to account for the effects of different unresolved physical processes, e.g. submesoscale effects for eddying models). Numerical algorithms used to solve the equations may also need to be adapted to the new physical processes arising, although the formulation of the problem does not change. This latter aspect that links resolution and numerics is illustrated in this part of the course with the momentum advection scheme. The momentum equation of the PEs, written in a standard form (see appendix for notations), is:

\section{Zonal momentum}

$$
\frac{\partial u}{\partial t}+(\mathbf{u} \cdot \nabla) u-f v=-\frac{1}{\rho_{0}} \frac{\partial P}{\partial x}+D_{u}+F_{u}
$$

Meridional momentum

$$
\frac{\partial v}{\partial t}+(\mathbf{u} \cdot \nabla) v+f u=-\frac{1}{\rho_{0}} \frac{\partial P}{\partial y}+D_{v}+F_{v}
$$

The $(\mathbf{u} \cdot \nabla) u$ and $(\mathbf{u} \cdot \nabla) v$ terms in (17) are non linear terms that represent the advection of momentum by the flow. There is a variety of numerical schemes to calculate these terms in finite differences, and we illustrate here the impact they can have on the solution of a numerical model. 
We are comparing the effects of three different 2 nd order advection schemes on the solution of an eddy permitting $\left(1 / 4^{\circ}\right)$ model that uses the NEMO OGCM (Madec 2008). The schemes (presented in detail in (Le Sommer et al. 2009)) have different mathematical formulations that are shortly described hereafter:

- The EFX scheme: written in the form of a divergence of a flux, this scheme is energy conserving.

- The ENS scheme: written in the form of a gradient of kinetic energy and a vorticity term, this scheme is enstrophy conserving.

- The EEN scheme: also written in the form of a gradient of kinetic energy and a vorticity term, it uses a larger stencil than ENS. This scheme is energy and enstrophy conserving.

Sensitivity experiments to these advection schemes have been performed with the Drakkar model configurations (based on the NEMO OGCM (Madec 2008), see section 4$)$. Coarse-resolution (laminar) configurations $\left(2^{\circ}\right.$ or $\left.1^{\circ}\right)$ showed a weak sensitivity to the choice of the scheme, as expected from the minor contribution of $(\mathbf{u} \cdot \nabla) u$ terms at large scales (very small Rossby number). However, the eddy permitting configuration $\left(1 / 4^{\circ}\right)$ proved to be very sensitive to this choice, as illustrated in Fig. 3. The simulated mean circulation is significantly modified in pattern and amplitude in regions of strong currents. The Gulf Stream for example is significantly shifted southward with the EEN scheme compared to the ENS scheme (Fig. 3).

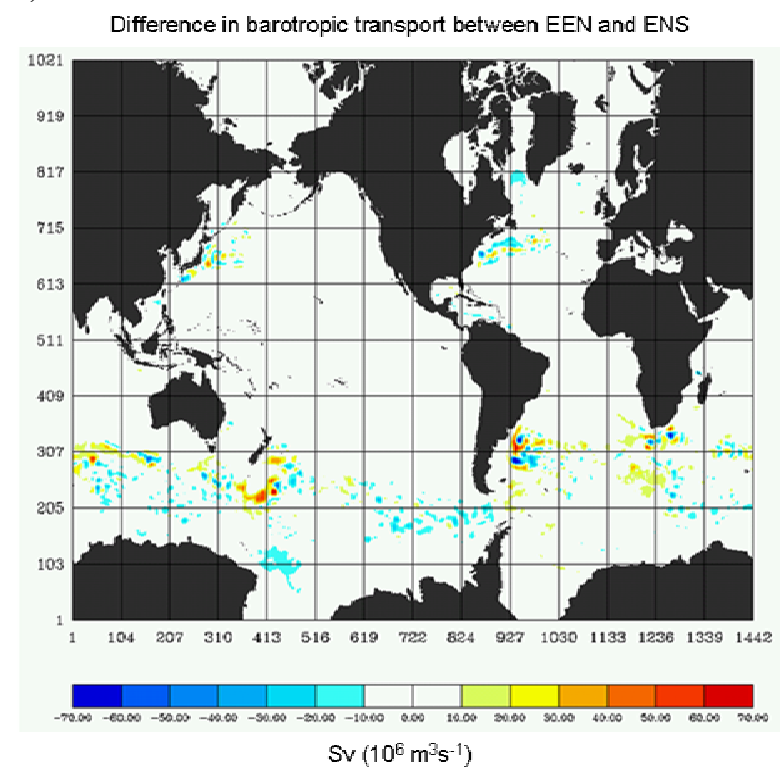

Fig. 3. Difference in the mean barotropic streamfunction between two simulations performed with the ORCA025 $\left(1 / 4^{\circ}\right)$ Drakkar model. One simulation is using the EEN momentum advection scheme and its twin is using the ENS momentum advection scheme (the difference EEN minus ENS is shown). Large differences (i.e. greater than $\pm 10 \mathrm{~Sv}$ ) are only found in regions of strong nonlinear currents. 
As demonstrated by (Le Sommer et al. 2009), compared to the two other schemes, the EEN scheme was found to reduce the noise in the vertical velocity field near the bottom cells. Enhanced continuity of the mean currents and enhanced topographic rectification effects were also diagnosed with the EEN scheme. This might have contributed to improved western boundary currents and to the significant reduction of the inertial eddy at Cape Hatteras (see also Barnier et al. 2006, Penduff et al. 2007).

The momentum advection scheme was also found to impact the trajectory of Agulhas Rings in the Benguela Basin (Barnier et al. 2006). These trajectories tend to be spuriously straight, deterministic and invariable in several eddying models, including the POP model $\left(1 / 10^{\circ}\right)$ and the $1 / 4^{\circ}$ Drakkar model with ENS. The use of the EEN scheme in the $1 / 4^{\circ}$ Drakkar model substantially reduced this widelyfound inconsistency, yielding much more realistic (i.e. more chaotic and irregular) Ring shedding events and trajectories in the South Atlantic, as shown by the patterns of eddy kinetic energy (Fig. 4). Other examples (Barnier et al. 2006) (Penduff et al. 2007) confirm that the use of advanced numerical schemes (such as the use of a partial step representation of topography in z-coordinate models) may improve model solutions in a more drastic way than an increase in resolution.

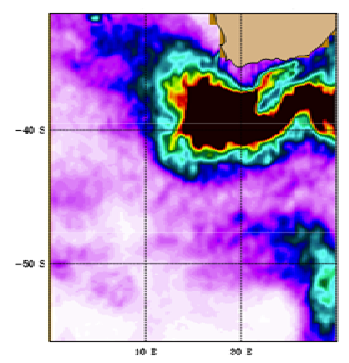

a) Satelite altimetry

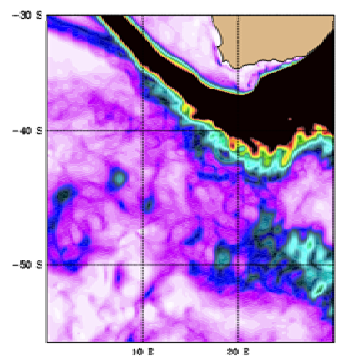

c) POP $1110^{\circ}$

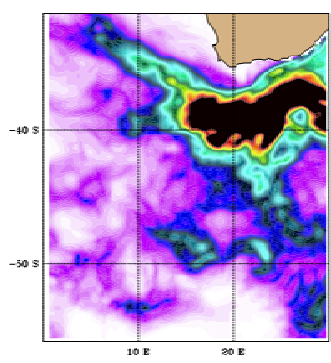

b) ORCA025 with EEN

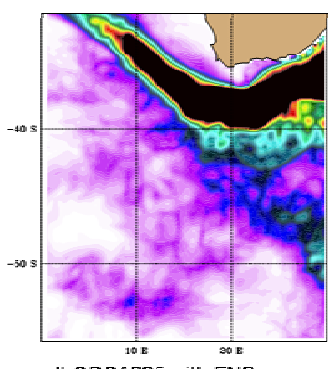

di ORCAO25 with ENS

Fig. 4. Mean surface eddy kinetic energy (eke in $\mathrm{cm}^{2} \mathrm{~s}^{-2}$ ) around South Africa, a) as observed by satellite altimetry (Ducet et al. 2000), and as simulated by $b$ ) the global ORCA025 Drakkar model with the EEN scheme, $c$ ) the global POP $1 / 10^{\circ}$ global model, and $d$ ) the global ORCA025 Drakkar model with the ENS scheme. All model results show velocity variances computed over 3 years. 


\section{Impact of resolution on model solution}

In this part of the course, we use the Drakkar hierarchy of global ocean circulation models that spans resolutions from $2^{\circ}$ to $1 / 12^{\circ}$ to illustrate how the changes in resolution impact the realism of model simulations.

\subsection{DRAKKAR hierarchy of model configurations}

Drakkar is a cooperation that gathers the resources and expertise of several research and operational oceanography groups in Europe with the objective to develop, share and improve a hierarchy of global ocean/sea-ice model configurations that can be used for research and operational applications (Drakkar Group 2007). Drakkar uses the NEMO modelling system (Madec, 2008) ${ }^{1}$ and the AGRIF grid refinement software (Debreu et al., 2008) ${ }^{2}$. Drakkar also contributes to the continuous development of NEMO.

Drakkar has implemented a hierarchy of global and regional NEMO configurations using the tripolar ORCA grid (Madec and Imbard 1996), (Fig. 5). Global simulations have been performed at $2^{\circ}, 1^{\circ}, 1 / 2^{\circ}, 1 / 4^{\circ}$, and $1 / 12^{\circ}$ horizontal resolution. Every configuration uses domain decomposition (up to $\sim 1000$ processors) to run on massively parallel computers. The main characteristics of the model hierarchy are summarized in Table 1 . A detailed description of the $1 / 4^{\circ}$ ORCA025 configuration and of the model hierarchy may be found in (Barnier et al. 2006) and (Penduff et al. 2010), respectively.

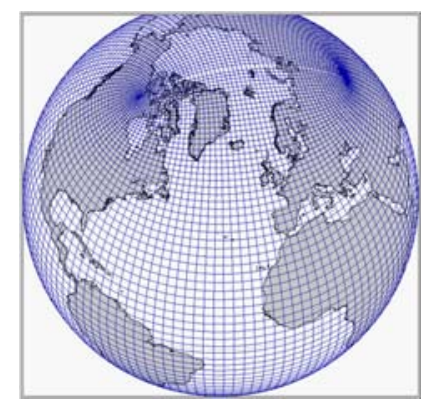

Fig. 5. Tripolar grid of the DRAKKAR ORCA025 configuration $\left(1 / 4^{\circ}\right.$ resolution at the equator) with 1 point every 12 points plotted (in total $1442 \times 1021$ grid points). This eddy permitting configuration is used by MERCATOR-Ocean for operational forecasts.

\footnotetext{
1 NEMO includes an ocean model, a sea-ice model, and a module simulating the evolution of geochemical passive tracers (i.e. ${ }^{14} \mathrm{C}, \mathrm{CFC}^{11}, \mathrm{SF} 6$ ).

2 See (Biastoch et al. 2009) for an example on application of AGRIF in the Agulhas retroflection region, (Chanut et al. 2009) for an application in the Labrador Sea, or (Jouanno et al. 2008) in the Caribbean Seas.
} 
The bulk formulae used in the forcing function are those proposed by (Large and Yeager 2004). The atmospheric forcing fields used in the Drakkar simulations come from the CORE data set (Large and Yeager 2008), and from the Drakkar Forcing Sets DFS3 or DFS4 (Brodeau et al. 2010). The DFS forcing uses ERA40 6 hourly surface atmospheric variables to calculate the turbulent fluxes (wind stress, latent and sensible heat fluxes, evaporation), daily satellite radiation fluxes (for downward short wave and long wave) and monthly precipitation from satellite estimates. The various corrections applied to these data are described in (Brodeau et al. 2010). Note that recent developments introduced the diurnal cycle of solar radiation and the contribution of the ocean biology to the depth-dependant absorption of light. Most Drakkar simulations cover the period 1958 to 2004 (Drakkar Group 2007). Most simulations used in this course are from the G70 series, in which the $2^{\circ}, 1^{\circ}, 1 / 2^{\circ}$ and $1 / 4^{\circ}$ Drakkar models have been driven with the DFS3 forcing over the 50 year period 1958 to 2007 .

Table 1. Table 1: Main settings of the ocean component of the Drakkar hierarchy of global model configurations. The setting of the LIM2 sea ice model (Fichefet et al. 1997) is not described here.

\begin{tabular}{lll}
\hline 46 to 75 vertical levels & Topography & Advection scheme \\
\hline Surface: $6 \mathrm{~m}$ to $1 \mathrm{~m}$ & Partial steps & $\begin{array}{l}\text { Momentum: EEN } \\
\text { Bottom: } 250 \mathrm{~m} \text { to } 200 \mathrm{~m}\end{array}$ \\
\hline
\end{tabular}

\begin{tabular}{llll}
\hline Horizontal mixing & $2^{\circ}-1^{\circ}$ models & $1 / 2^{\circ}-1 / 4^{\circ}$ models & Particularity \\
\hline \multirow{2}{*}{ Momentum } & horizontal laplacian & horizontal bilaplacian & \\
& $\mathrm{K}_{\mathrm{v}}=4 \times 10^{4}$ to $1 \times 10^{4} \mathrm{~m}^{2} \mathrm{~s}^{-1}$ & $\mathrm{~K}_{\mathrm{v}}=12 \times 10^{11}$ to & grid dependent \\
& Isopycnal laplacian & Isopycnal laplacian & \\
T,S, Tracers & $\mathrm{K}_{\mathrm{T}}=1000 \mathrm{~m}^{2} \mathrm{~s}^{-1}$ & $\mathrm{~K}_{\mathrm{T}}=600$ to $300 \mathrm{~m}^{2} \mathrm{~s}^{-1}$ & grid dependent \\
Eddy & $\mathrm{GM} 90$ & None & GM90 in few $1 / 2^{\circ}$ \\
parameterisation & $\mathrm{K}_{*}=2000$ to $1000 \mathrm{~m}^{2} \mathrm{~s}^{-1}$ & & runs \\
\hline
\end{tabular}

\begin{tabular}{llll}
\hline Vertical mixing & $\mathrm{T}, \mathrm{S}$, Tracers & Momentum & Particularity \\
\hline Background & $\mathrm{K}_{\mathrm{T}}=10^{-5} \mathrm{~m}^{2} / \mathrm{s}$ & $\mathrm{K}_{\mathrm{v}}=10^{-4} \mathrm{~m}^{-2} / \mathrm{s}$ & $\left(10^{-6}\right.$ under sea ice $)$ \\
Turbulent closure & $\mathrm{TKE}$ scheme & $\mathrm{TKE}$ scheme & $\begin{array}{l}\text { Parameterisation of wave } \\
\text { breaking and Langmuir cells }\end{array}$ \\
Convection & $\mathrm{K}_{\mathrm{T}}=10 \mathrm{~m}^{2} \mathrm{~s}^{-1}$ & $\mathrm{~K}_{\mathrm{v}}=10 \mathrm{~m}^{2} \mathrm{~s}^{-1}$ & Enhanced vertical diffusion \\
\hline
\end{tabular}




\begin{tabular}{llll}
\hline Boundary conditions & Side wall & Bottom & Surface \\
\hline parameterisation & free-slip & Quadartic drag law $\left(\mathrm{C}_{\mathrm{D}}=10^{3}\right)$ & Flux form \\
& & & - Bulk formulas \\
& & & - CORE forcing \\
Particularity & no slip at $2{ }^{\circ}$ Internal tides mixing & Diffusive and advective BBL & - DFS forcing sets \\
& & & - Surface Salinity \\
& & & relaxation \\
\hline
\end{tabular}

These simulations are compared to 2 observational references: the in-situ ENACTENSEMBLES hydrographic database (EN3-v2a, Ingleby and Huddleston 2007), and the AVISO altimetric (SLA) database. For that purpose, a collocation algorithm based on a quadrilinear interpolation scheme in space and time subsamples the model outputs in the exact same way as the observations; dedicated metrics are then used to compare observed and simulated collocated databases (see Fig. 6).
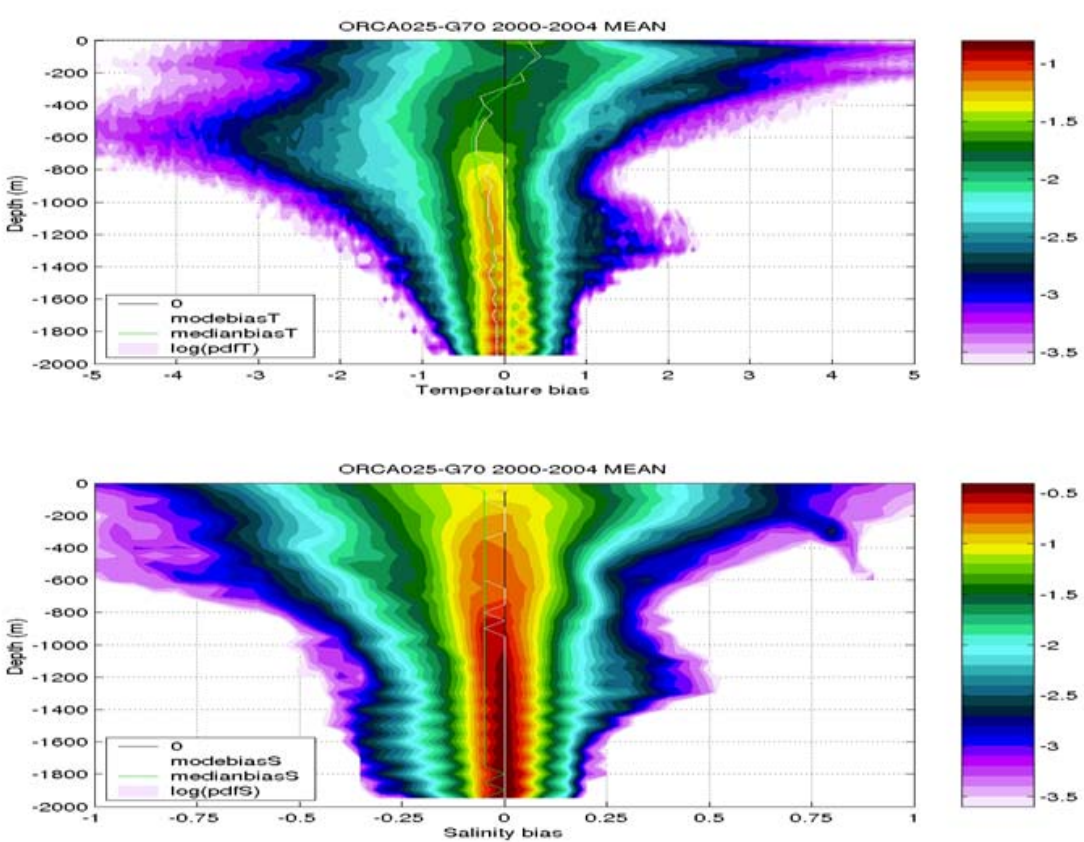

Fig. 6. Vertical structure of model temperature (top) and salinity (bottom) biases (relative to the period 2000-2004) in the ORCA025 Drakkar simulation driven with the DFS3 forcing (run series G70). The reference is the EN3-v2a hydrographic data set. In colour are the PDFs (in log scale) of temperature and salinity biases (x-axis) as a function of depth (y-axis). The median (green line) and the mode (white line) of these depth-dependent PDFs are superimposed (M. Juza, personal communication). 


\subsection{Some impacts of resolution increase}

The Drakkar hierarchy of models proved very useful to assess the impact of grid resolution on the representation of climate-relevant ocean circulation features. Fig. 1a shows an altimeter observation of the global sea-level anomaly (SLA) averaged over a week in May 2004, with a strong signature of mesoscale eddies. These mesoscale features are obviously absent at $2^{\circ}$ (Fig. 1c), but are clearly visible and exhibit realistic patterns at $1 / 4^{\circ}$ (Fig. $1 \mathrm{~b}$ ): from this mesoscale perspective, laminar and eddying ocean models do not simulate the "same" ocean. It is more interesting and relevant to compare these two classes of models with a focus on relatively large-scale features that are captured by both, such as basin-scale integrated climate indices, spatially-smoothed mean horizontal circulation, and interannual variability (LSIV) patterns.

The zonally-averaged meridional overturning circulation (MOC) and meridional heat transport (MHT) exhibit certain sensitivity to resolution changes. While the meridional structure of the Atlantic MOC is barely changed from $2^{\circ}$ to $1 / 4^{\circ}$ (Fig. 7), the mean amplitudes of the MOC and MHT increase by about $25 \%$ (Table 2).

Table 2: Atlantic MOC and MHT estimated at $26^{\circ} \mathrm{N}$ by the various models of the Drakkar hierarchy, all driven by the same DFS3 forcing.

\begin{tabular}{lll}
\hline Resolution & Atlantic MOC $\left(26^{\circ} \mathrm{N}\right)$ & Atlantic MHT $\left(26^{\circ} \mathrm{N}\right)$ \\
\hline $2^{\circ}$ model & $13 \mathrm{~Sv}$ & $0.68 \mathrm{PW}$ \\
$1^{\circ}$ model & $16 \mathrm{~Sv}$ & $0.73 \mathrm{PW}$ \\
$1 / 2^{\circ}$ model & $17 \mathrm{~Sv}$ & $0.80 \mathrm{PW}$ \\
$1 / 4^{\circ}$ model & $17 \mathrm{~Sv}$ & $0.88 \mathrm{PW}$ \\
\hline
\end{tabular}

However, the low-frequency variability of the MOC (Fig. 8) is remarkably similar among all simulations: although other climatic indices may differ significantly, this result shows that eddying models might not yield major changes in the simulation of the slow evolution of the MOC and MHT.

Fig. 9 compares the time-averaged, vertically-integrated (barotropic) streamfunction simulated by a $2^{\circ}$ model and a $1 / 12^{\circ}$ model. The solution of the $1 / 12^{\circ}$ model has been smoothed and plotted onto the $2^{\circ}$ grid. Both models roughly agree on the location of large scale gyres and the mean currents, but many differences can be seen in the horizontal circulation, e.g. the structure and extent of the subpolar gyre of the North Atlantic, the Confluence in the western South Atlantic, or the frontal structure of the Antarctic Circumpolar Current. Clearly, resolution significantly improves the realism of the simulated western boundary currents, the location of permanent fronts, and the amplitude of current velocities and transports. 
Since many of these improvements appear in regions of atmospheric cyclogenesis, one may expect significant (and potentially beneficial) changes between ocean/atmosphere coupled simulations using coarse and eddying ocean models.

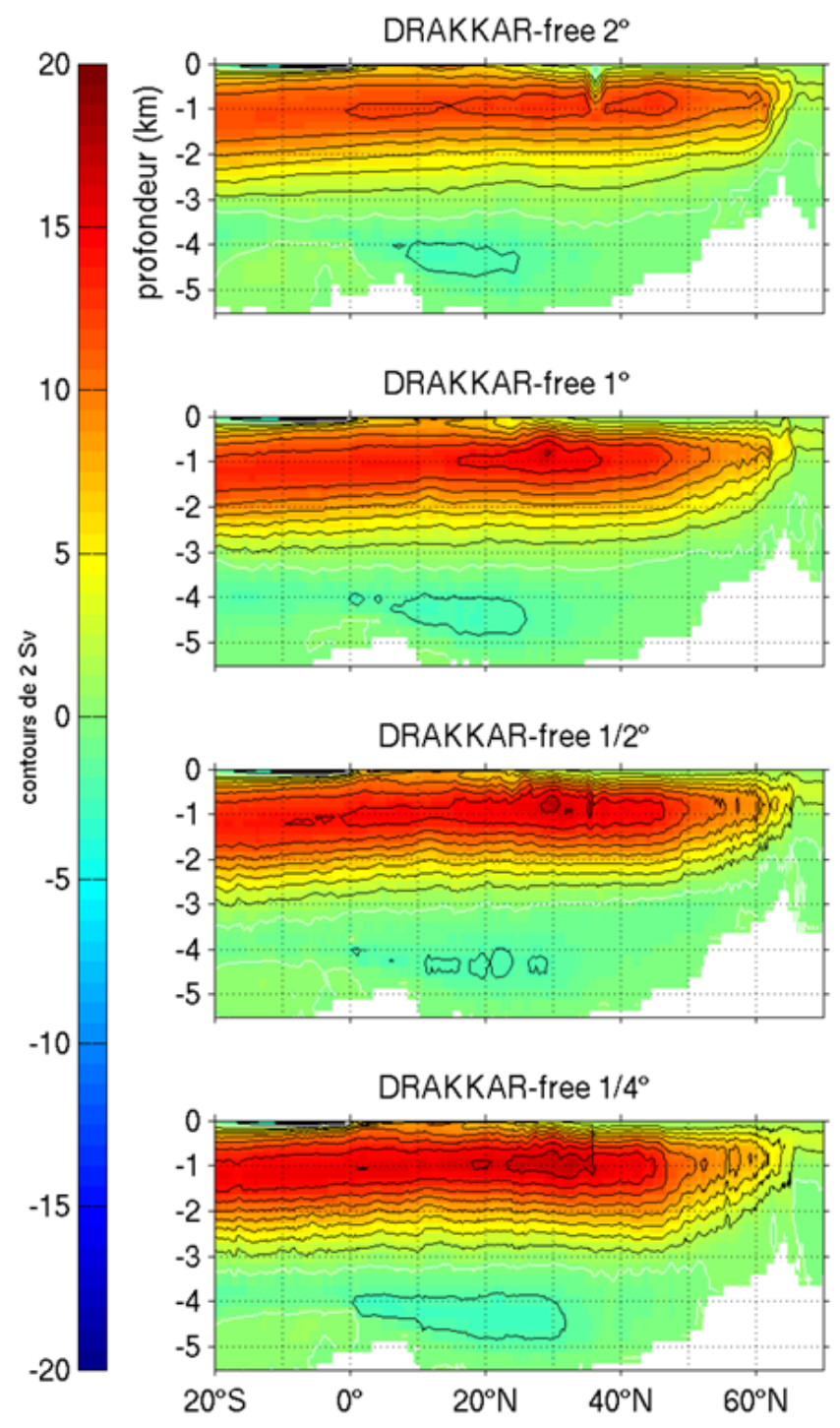

Fig. 7. Mean meridional overturning streamfunction in the Atlantic obtained in 4 Drakkar simulations at increasing resolutions $\left(2^{\circ}, 1^{\circ}, 1 / 2^{\circ}\right.$ and $\left.1 / 4^{\circ}\right)$, driven with the same DFS3 forcing (run series G70). Contour interval is $2 \mathrm{~Sv}$ (Lecointre 2009). 


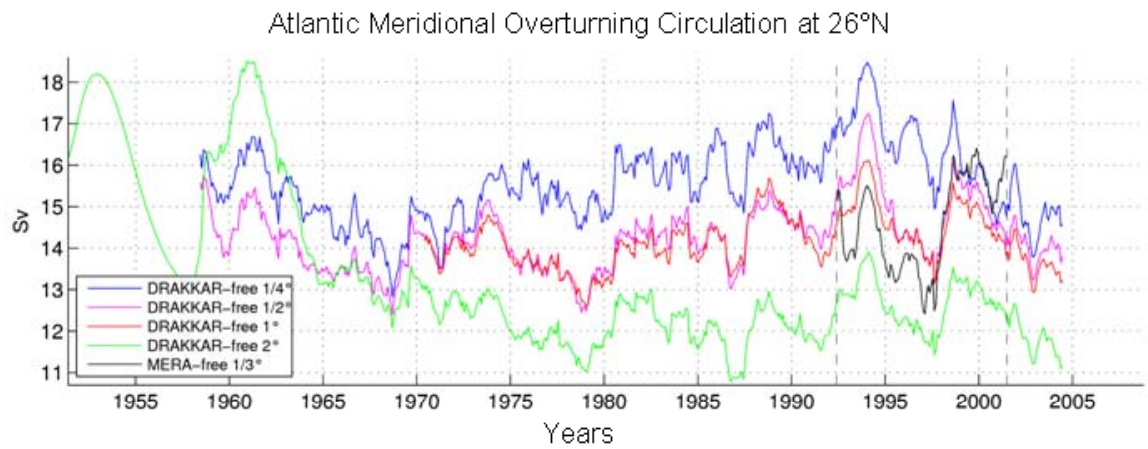

Fig. 8. Monthly mean variations of the Atlantic MOC (in Sv) at $26^{\circ} \mathrm{N}$ between 1958 and 2004 in 4 Drakkar simulations of increasing resolution $\left(2^{\circ}, 1^{\circ}, 1 / 2^{\circ}\right.$ and $\left.1 / 4^{\circ}\right)$. All simulations are driven by the same DFS3 forcing (run series G70). The value of the AMOC is the value at $1000 \mathrm{~m}$ of the overturning streamfunction shown in Fig. 8. The MERA curve comes from a regional model of the North Atlantic at $1 / 3^{\circ}$ resolution (Lecointre 2009). The $2^{\circ}$ model (green line) has a different spin-up strategy than the other models, which explains for its peculiar behaviour between 1950 and 1965.

Penduff et al. (2010) low-pass filtered observed and Drakkar simulations timedependant SLA fields over 1993-2004 to compare model skills in terms of largescale interannual variability (LSIV), i.e. at scales larger than about $6^{\circ}$ and timescales longer than 1.5 year. Successive increases in model resolution from $2^{\circ}$ to $1 / 4^{\circ}$ were shown to yield systematic improvements in LSIV features, in particular stronger interannual variability, and systematic improvements in its geographical patterns. Again, this suggests that the (partial) resolution of mesoscale features yields more accurate eddy fluxes than mesoscale parameterizations, not only regarding the mean state but also its low-frequency variability. While basinintegrated quantities are moderately sensitive to resolution changes in this setup, their spatial and temporal patterns (hence their underlying dynamical origin) are strongly improved when the grid size decreases.

\section{Conclusion}

In this course, we have used satellite observations to illustrate the ubiquity of mesoscale variability in the ocean, in every basin and at all latitudes. We have provided a dynamical definition of the ocean mesoscale based on scaling arguments that links the mesoscale to the general circulation and provides a characteristic scale of motion. We listed the mesoscale processes that may have important consequences for the ocean general circulation and climate. On the modelling side, two ways of dealing with the eddy problem were presented. One is to resolve eddies (partially to fully) with computationally expensive fine grids, another is to 
parameterise eddies on coarse but computationally efficient grids. This brought up the concept of resolved/unresolved scales, an ocean model providing a solution for the scales it resolves that depends on the representation of the unresolved scales.

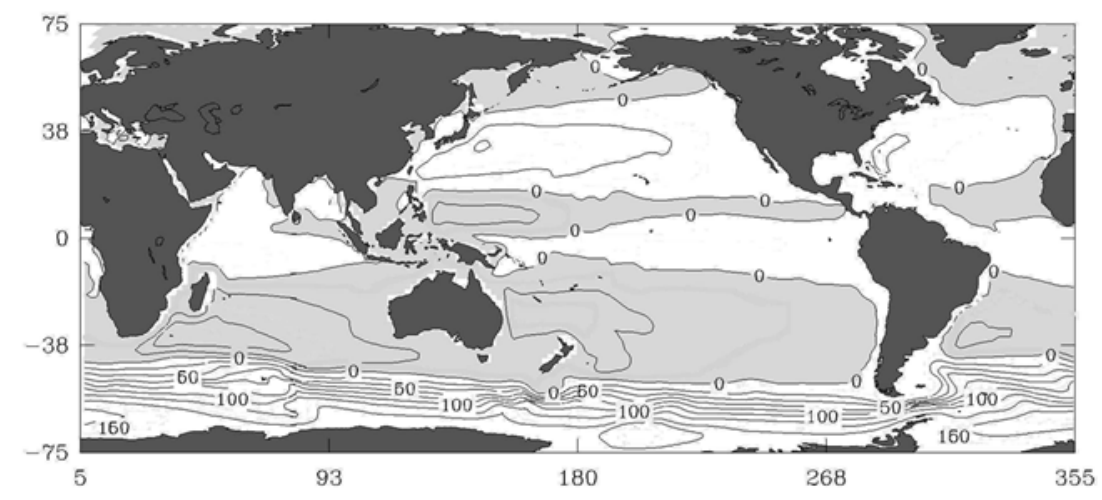

a) Drakkar $2^{\circ}$ model

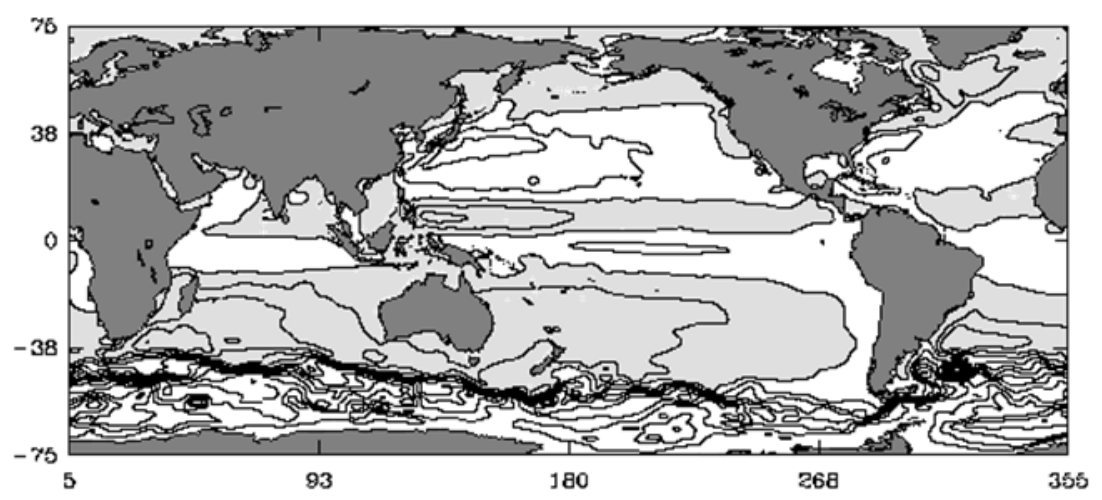

a) Drakkar $1 / 12^{\circ}$ model

Fig. 9. Mean barotropic transport streamfunction simulated by a) the $2^{\circ}$ resolution model ORCA2, and b) the $1 / 12^{\circ}$ resolution model ORCA12 (contour interval of $20 \mathrm{~Sv}$ ). For this comparison the $1 / 12^{\circ}$ solution has been smoothed with a 100 pass of a Hanning filter and plotted on the $2^{\circ}$ grid.

We have explained that the representation of the unresolved scales requires a "closure hypothesis" based on a physical ground which is very different in laminar and eddying models. Both types of model solve the same equations: similar numerical schemes may be used for both. However, examples illustrate different sensitivities of model solutions to numerical schemes depending on resolution: as expected, high-resolution models show greater sensitivity to the numerical schemes used to solve non-linear terms (e.g. the momentum advection scheme). Therefore, ways of 
model development should strongly associate resolution increase with improvement of numerical schemes and parameterisation of subgrid scales.

Although they solve for the same equations, eddying and laminar models do not simulate the "same" ocean, for physical and numerical reasons. An example was shown where the coarse resolution solution and the spatially-smoothed high resolution solution are not equivalent (i.e. parameterisations are still not fully representing the unresolved scales). Increased resolution lets mesoscale turbulence develop hence improves the consistency of resolved physics and the realism of model solutions, especially the path of strong currents, their link with topography, the amplitude of current velocities, and the main features of interannual variability. However, some climate-relevant integrated quantities, such as the AMOC and the MHT seem relatively less sensitive to resolution (e.g. the AMOC mean pattern and its interannual variability). However, since air-sea interactions are localized, these results suggest that eddying ocean models should contribute to improve the physical consistency of future climate prediction systems.

To conclude this course, one should emphasise that (mesoscale) eddyresolution modelling is still in its infancy. Today's "eddy-resolving" global model resolutions reach $1 / 12^{\circ}$ at the equator, but very few are used routinely today (most have coarser grids, i.e. up to about $1 / 4^{\circ}-1 / 10^{\circ}$ ). More generally, the sensitivity of eddying global models to forcing, parameters or numerical schemes remains largely unknown, and various research groups are still working on the parameterisation of unresolved (sub-mesoscale) features. Practically, the computational cost and storage requirements of eddying global models are large (even for present super-computers): a challenge for the next 10 years might be to carry out the transition from $\mathrm{O}\left(1 / 4^{\circ}-1 / 10^{\circ}\right)$ to $\mathrm{O}\left(1 / 12^{\circ}-1 / 16^{\circ}\right)$ routine climate-oriented large-scale simulations. Because of computer limitations, climate models used in 10000-year paleo-climatological hindcasts use (laminar) ocean components at coarser resolutions than those used for 100-year IPCC-like predictions. In turn, the resolution of these coupled ocean models cannot be as fine as those presently developed in Drakkar-like ocean-only eddying setup, and in operational models that are being presently used at much higher resolution, (e.g. $1 / 32^{\circ}$ or more) on regional domains. Coarse-resolution models, on one hand, continuously benefit from parameterisations developed from high-resolution model. On the other hand, these models are efficient tools to improve certain eddying ocean model components (e.g. atmospheric forcing), and coupled ocean/atmosphere models provide eddying ocean modellers with essential feedbacks on air-sea interactions. In conclusion, "laminar", "eddy-permitting", and "eddy-resolving" ocean models require coordinated development efforts since ocean modellers need a large range of tools depending on applications.

\section{Acknowledgments}

We acknowledge the continuous support provided to the MEOM ocean modelling group in Grenoble by CNRS and CNES, and the very important support in supercomputing provided by GENCI (IDRIS and CINES). Support for this course has been provided by GMMC. Bernard 
Barnier is very grateful to Clothilde Langlais who prepared and taught the practical work on the GM90 parameterisation associated to this course, and to Tim Pugh who set the computer facilities for the practical work so efficiently. We would like to thank Jean Marc Molines, Mélanie Juza and Albanne Lecointre who provided important material for the course, and Anne Marie Treguier and Gurvan Madec, our partners in the Drakkar coordination.

\section{References}

Barnier, B., Madec, G., Penduff T., Molines, J.-M., Treguier, A.M., Le Sommer, J., Beckmann, A., Biastoch, A., Böning, C., Dengg, J., Derval, C., Durand, E., Gulev, S., Remy, E., Talandier, C., Theetten, S., Maltrud, M., McClean, J., De Cuevas, B.: Impact of partial steps and momentum advection schemes in a global ocean circulation model at eddy permitting resolution. Ocean Dynamics (2006). doi: 10.1007/s10236-006-0082-1.

Biastoch, A., Böning, C.W., Lutjerharm,s J.R.E.: Agulhas leakage dynamics affects decadal variability in Atlantic overturning circulation. Nature (2008). doi: 10.1038/nature07426.

Brodeau, L., Barnier, B., Penduff, T., Treguier, A.M., Gulev, S.: An ERA40 based atmospheric forcing for global ocean circulation models. Ocean Modelling. 31, 88-104 (2010)

Chanut, J., Barnier, B., Large, W., Debreu, L., Penduff, T., Molines, J.M., Mathiot, P.: Mesoscale eddies in the Labrador Sea and their contribution to convection and restratification. Journal of Physical Oceanography, 38, 1617-1643 (2008)

Chelton, D.B., Schlax, M.G., Samelson, R.M., de Szoeke, R.: Global observations of large oceanic eddies. Geophys. Res. Letters (2007). doi:10.1029/2007 GL030812.

Ducet, N., Le Traon, P.Y., Reverdin, G.: Global high resolution mapping of ocean circulation from Topex/Poseidon and ERS-1 and -2. J. Geophys. Res. - Ocean. 105 (C8): 19477-19498 (2000)

DRAKKAR Group: Eddy-permitting Ocean Circulation Hindcasts of past decades. CLIVAR Exchanges. No 42, 12(3), 8-10 (2007)

Eden, C., Greatbatch, R.J.: Towards a mesoscale eddy closure. Ocean Modelling, 20, 223-239 (2008)

Fichefet, T., Morales Maqueda, M.A.: Sensitivity of a global sea ice model to the treatment of ice thermodynamics and dynamics. J. Geophys. Res. 102: 12609-12646 (1997)

Frisch, U., Kurien, S., Pandit, R., Pauls, W., Ray, S., Wirth, A., Zhu, J.-Z.: Hyperviscosity, Galerkin truncation, and bottlenecks in turbulence. Physical Review Letters, 101, 144501 (2008)

Gent, P.R., McWillams, J.C.: Isopycnal mixing in ocean circulation models. J. Phys. Oceanogr. 20: $150-155$ (1990)

Griffies, S.M.: Fundamentals of ocean climate models, Princeton University Press, Princeton, USA, 518+xxxivpages, 2004.

Griffies, S.M., Gnanadesikan, A., Dixon, K.W., Dunne, J.P., Gerdes, R., Harrison, M.J., Rosati, A., Russell, J.L., Samuels, B.L., Spelman, M.J., Winton, M., Zhang, R.: Formulation of an ocean model for global climate simulations. Ocean Science, 1, 45-79 (2005)

Griffies, S. M., Adcroft, A. J.: Formulating the equations of an ocean model. In Ocean Modeling in an eddying regime, Geophysical Monograph 177, M. W. Hecht, H. Hasumi, editors, Washington DC: American Geophysical Union, 281-318 (2008)

Ingleby, B., Huddleston, M.: Quality control of ocean temperature and salinity profiles from historical and real-time data. J. Marine Systems (2007). doi:10.1016/j.jmarsys.2005.11.019.

Jouanno, J., Sheinbaum, J., Barnier, B., Molines, J.M., Debreu, L., Lemarié, F.: The mesoscale variability in the Caribbean Sea. Part I: simulations with an embedded model and characteristics. Ocean Modelling, 23, 82-101 (2008)

Juza, M., Penduff, T., Barnier, B., Brankart, J.M.: Analysis of monthly ARGO sampling errors in the global ocean mixed layer: a DRAKKAR model study. In preparation (2010) 
Large, W.G., McWilliams, J.C., Doney, S.C.: Oceanic vertical mixing: A review and a model with a non local boundary layer parameterization. Reviews of Geophysics, 32, 363-403 (1994)

Large, W.G.: Modeling and parameterizing the ocean planetary boundary layer. E.P. Chassignet and J. Verron (eds.), Ocean Modeling and parameterization, 81-120. Kluwer Academic Press (1998)

Large W.G., Yeager S.G.: Diurnal to decadal global forcing for ocean and sea-ice models: the data sets and flux climatologies. NCAR technical note: NCAR/TN-460+STR. CGD division of the National Center for Atmospheric Research (2004)

Large, W.G., Yeager, S.G.: The global climatology of an interannually varying air-sea flux data set. Clim.Dyn (2008). doi: 10.1007/s00382-008-0441-3.

Lecointre, A.: Variabilité océanique interannuelle dans l'océan Atlantique Nord: simulation et observabilité. Thèse de l'Université Joseph Fourier, Grenoble (2009). http://tel.archivesouvertes.fr/tel-00470520/

Lesieur, M.: Turbulence in fluids, 4th Edition, FMIA 84, R. Moreau Series Ed., Springer (2008), ISBN 978-1-4020-6434-0.

Le Sommer J, Penduff T., Theetten S., Madec G., and Barnier B., 2009: How momentum advection schemes influence current-topography interactions at eddy permitting resolution, Ocean Modelling, 29, 1-14.

Madec G, Imbard M (1996) A global ocean mesh to overcome the North Pole singularity. Climate Dyn, 12, 381-388

Madec, G., 2008: NEMO, the ocean engine, Notes de l'IPSL, Universit e P. et M. Curie, B102 T15-E5, 4 place Jussieu, Paris cedex 5.

McWilliams J. C., 2008: The nature and consequences of oceanic eddies. In Ocean Modeling in an eddying regime, Geophysical Monograph 177, M. W. Hecht, H. Hasumi, editors, Washington DC: American Geophysical Union, 5-15.

Müller, P.: The Equations of Oceanic Motions. Cambridge University Press (2006), 291 pp.

Penduff T., J. Le Sommer, B. Barnier, A.-M. Treguier, J.-M. Molines, and G. Madec, 2007: Influence of numerical schemes on current-topography interactions in $1 / 4^{\circ}$ global ocean simulations. Ocean Science, Vol. 3, No 4, 451-535.

Penduff T., Juza M., Brodeau L., Smith G.C., Barnier B., Molines J.-M., A.-M. Treguier and G. Madec, 2010: Impact of model resolution on sea-level variability with emphasis on interannual time scales. Ocean Science, 6, 269-284.

Redi, M. H., 1982: Oceanic isopycnal mixing by coordinate rotation. J. Phys. Oceanogr., 12, 1154-1158.

Treguier, A. M., 2006: Models of the ocean: which ocean? E.P. Chassignet and J. Verron (Eds.), Ocean Weather Forecasting, 75-108. Springer.

Zhao, R., and G. Vallis, 2008: Parameterizing mesoscale eddies with residual and Eulerian schemes, and a comparison with eddy-permitting models. Ocean Modelling, 23, 1-12.

\section{Appendix}

Formulation of the Primitive Equations in the usual Cartesian coordinate system $(\mathrm{x}, \mathrm{y}, \mathrm{z})$ used in the course.

\section{Definitions}

$T=$ potential temperature $\quad S=$ Salinity $\quad \rho=$ density 
$\mathbf{u}=(u, v, w)=$ velocity vector $\quad P=$ pressure

$f=$ Coriolis parameter $\quad g=$ gravitational acceleration

$D_{T, S, u, \mathrm{v}}=$ diffusion/dissipation terms $\quad F_{T, S, u, \mathrm{v}}=$ forcing terms

$(x, y, z)=$ coordinate system (eastward, northward, upward)

$\nabla=(\partial / \partial x, \partial / \partial y, \partial / \partial z)=$ gradient vector operator

\section{Equations}

Zonal momentum

$\frac{\partial u}{\partial t}+(\mathbf{u} \cdot \nabla) u-f v=-\frac{1}{\rho_{0}} \frac{\partial P}{\partial x}+D_{u}+F_{u}$

Meridional momentum

$\frac{\partial v}{\partial t}+(\mathbf{u} \cdot \nabla) v+f u=-\frac{1}{\rho_{0}} \frac{\partial P}{\partial y}+D_{v}+F_{v}$

Temperature

Salinity

$\frac{\partial T}{\partial t}+\mathbf{u} \cdot \nabla T=D_{T}+F_{T}$

$\frac{\partial S}{\partial t}+\mathbf{u} \cdot \nabla S=D_{S}+F_{S}$

Hydrostatic approximation

$\frac{\partial P}{\partial z}=-\rho g$

Non divergence of the velocity vector $\mathbf{u}=(u, v, w)$

$\nabla \cdot \mathbf{u}=0$

Nonlinear equation of state

$\rho=\rho(T, S, P)$ 